\title{
Sizing of a stand-alone photovoltaic power system at India
}

\author{
Ajay S. Tiwari \\ Department of Mechanical Engineering, Student of $4^{\text {th }}$ Sem ME Thermal, Gandhinagar Institute of \\ Technology, Gandhinagar, India
}

\begin{abstract}
A stand-alone photovoltaic power system is designed to operate residential appliances such as fluorescent lamp, and ceiling fan using standard methods. The total load is estimated for twelve hours of operation per day. The battery is sized considering different factors that affect battery efficiency to reliably operate the estimated loads during a sequence of below average insolation. The minimum battery size is obtained to be 130Ah, 12V. The PV array is sized to operate the load on a daily basis based on average weather conditions. The array is sized to proper values in order to operate the estimated load reliably in the month of minimum insolation taking into account different types of power losses.
\end{abstract}

Keywords: Solar Photovoltaic, Battery, Power, Current, Voltage, Ampere

\section{Introduction}

For utilizing solar energy efficiently and cost effectively proper design of reliable solar devices and system have to be attempted to suit our radiation climate and socioeconomic conditions. Solar energy reaches the earth in the form of radiation energy, which consists of photons. Radiation energy in the range of wave length $0.3-1.3$ micrometer [1] can be used to generate electricity through semiconductor devices, which are called photovoltaic solar cells, usually made of silicon, germanium, gallium arsenide, cadmium telluride, copper indium diselenide etc [2]. Direct conversion and storage of solar energy to electricity through the use of solar cell and electro chemical storage batteries offers an alternative and attractive method for providing electrical energy to remote villages in India, where conventional electric power supply is not available.

Apart from solar cells, the designing of a stand-alone photovoltaic power system (SPV) requires a number of other components such as array structure, mounting frames, inverters, control circuits, wiring and interconnections, storage battery etc.

The cost of accessories also system sizing, design, installation, checkout, testing and maintenance, etc. are important factors. All these can be lumped as balance of system cost (BOS). The design of a SPV system needs careful considerations of both solar cell and BOS components. We can also find out what combinations of array and battery sizes can be chosen to meet a desired reliability i.e. the substitution nature between array and battery. The first problem of sizing is thus to find the optimum combinations which minimize energy cost for a chosen reliability because a PV system with perfect reliability is over sized to meet relatively a short interval of time when it is faced with peak load or when there is cloudy weather. As the insolation, temperature and electricity requirements are different in different areas, designing of PV systems for different places have to be different.

Thus in spite of the many designs already made there is scope for many improvements to be made. Two of the most important of these improvements are: (i) Increase of solar cell output by choosing appropriate tilt and azimuth angle and (ii) minimization of required storage for remote applications. Optimizing these two factors results in a reduction of array and battery sizes, thus making stand alone photovoltaic systems (SPV) more economical and energy efficient [3]. In view of the great interest of PV power system designing, both for their technological applications and theoretical understanding of the mechanism involved, the present work is aimed at obtaining an optimum design of a stand-alone PV power system for residential uses. The main objectives have been the search for the best suited tilt angles, battery size, array size and parameters for optimum performance, to solve the problem of delivering electrical power at minimum cost. By optimizing the balancing parameters, sizes for both the solar array and battery capacity are determined which provide minimum life cycle cost. Reliability is vital to minimize the maintenance and repairing cost, particularly in remote areas, where there is a lack of spare parts and the necessary technical skills.

\section{System Sizing}

PV system sizing involves finding the cheapest combination of array size and storage capacity that will meet the anticipated load requirements with the minimum acceptable level of security. It can depend on widely application and the choices of the user or procurement agency. The following information is required for system sizing. (I) The daily or hourly load requirement during a typical day. (ii) Typical current and voltage characteristics of the selected type of module at various irradiances and temperatures. (iii) The mean daily 
irradiation on the plane of the array for every month of a typical year. (iv) The tilt factors for different tilt and azimuth angles. (v) The maximum number of consecutive sunless days likely to be experienced. (vi) The estimated cell temperature rise above ambient of the modules in the array. (vii) The required security of supply (viii) the selected DC bus voltage. (ix) The estimated percentage of energy losses in the battery, power conditioning equipment and control system. (x) The estimated losses in the array due to module mismatch, cable, dust and shading and voltage drop across blocking diodes.

The technique, we used for the designs is similar to those followed by Sandia National Laboratory, USA [4] and Siemens Solar, Germany. We have developed one design for storage days in order to get minimum battery and array size for the same required load. The design of our SPV power system for residential use is as follows: load estimation, determination of the PV array current and tilt angle, battery sizing and array sizing.

\section{- $\quad$ Selection Procedure for Battery}

Here are some units of measurement we might need to know before we start.

Battery Capacity in Amp hour (Ah)

Current drawn in Amps (I)

Time taken in Hours $(\mathrm{H})$

Voltage of power source in Volts (V)

Power in Watts (W)

So when choosing battery for our set up, we need to know how many amps we will be drawing and for how long.

An approximate measurement of a battery's ability to provide energy i.e. it's charge capacity, is its rating in ampere hours (Ah) or amp hours. So a 100 Ah battery will produce 100 amps for 1 hour. This capacity can be divided up any way you choose. 100 Ah could produce $1 \mathrm{amp}$ for 100 hours, or 50 amps for 2 hours, 4 amps for 25 hours or 25 amps for 4 hours etc.

Battery capacity $(\mathrm{Ah})=$ Current drawn $(\mathrm{I}) \times$ Time $(\mathrm{H})$

Or we could cross multiply and get.....

Time $=$ Battery capacity / Current drawn

Current drawn $=$ Battery capacity $/$ Time

So when choosing battery for your set up, you need to know how many amps you will be drawing and for how long.

There are other things that also need to be taken into consideration when calculating battery's capacity. When we discharge a battery by consuming the power stored in it, we should never discharge it beyond a certain point, otherwise risk damaging its future storage capacity. The maximum discharge level depends on the type and quality of the battery. A true deep cycle battery from an RV, golf cart or forklift truck etc. can be expensive but should have a discharge capacity of up to $80 \%$. Leisure batteries and marine batteries will be much less at around $50 \%$, but no matter how good the battery is, if we want it to last and not pack up after a few months of use, it is generally accepted that we should never discharge a battery by more than $50 \%$ of its capacity. We must also take into account, the battery's listed 'amp hour rating time' when we buy it, and the speed that we intend to drain the battery when we use it. These two factors can dramatically affect the battery's capacity.

Needing 100 watts capacity to run our Tube light and ceiling fan, and using a battery - inverter set up, we must also to take into consideration the inefficiencies of the inverter. Allowing for inverter efficiency of $90 \%$, therefore using an inefficiency factor of 1.1 we would need to put $100 \times 1.1=110 \mathrm{w}$ into the inverter to get $100 \mathrm{w}$ out the other side. So all in all, we need to buy a battery that can deliver 110 watts per hour for 12 hours. This will allow us to compensate for inverter losses and to only have to discharge the battery to $50 \%$ every time. If we purchase 12 volt batteries and need 110 watts for 12 hours, then we can work out the Ah rating of the batteries we need to buy. our system.

Battery Capacity $(\mathrm{Ah})=$ Current in Amps $(\mathrm{I}) \mathrm{x}$ Time $(\mathrm{H})$ we need to establish the current drawn (I) by $\mathrm{P}=\mathrm{V}$ I, Power (watts) $=$ Voltage $(\mathrm{V}) \times$ Current drawn in Amps (I)

$\mathrm{I}=\mathrm{P} / \mathrm{V}=110 / 12=9.1616 \mathrm{amps}$ So our battery capacity in Ah would need to be Battery Capacity $(\mathrm{Ah})=$ Current drawn $(\mathrm{A}) \times$ Time $(\mathrm{H})=9.1616 \times 12=109.9392=110 \mathrm{Ah}$. In this instance, we would need to have around $130 \mathrm{Ah}$ of battery power to do the job, cover losses and take care of our battery life. We could achieve this with 1 x $130 \mathrm{Ah} 12 \mathrm{v}$ batteries connected in parallel, giving us $130 \mathrm{Ah}$ at $12 \mathrm{v}$.

\section{- $\quad$ Power Factor}

For a DC circuit the power is $\mathrm{P}=\mathrm{VI}$ and this relationship also holds for the instantaneous power in an $\mathrm{AC}$ circuit. However, the average power in an $\mathrm{AC}$ circuit expressed in terms of the voltage/hr and current is = $P_{\text {avg }}=\cos \phi$ 

factor

Where $\phi$ is the phase angle between the voltage and current. The additional term is called the power

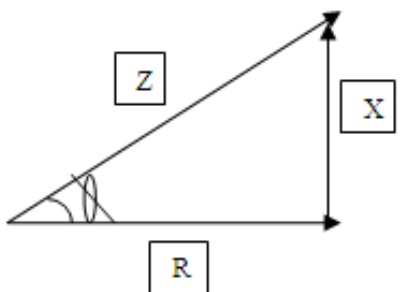

Fig.l Power Factor Diagram

POWER FACTOR $=\cos \phi=\frac{R}{Z}$

From the phasor diagram for $\mathrm{AC}$ impedance, it can be seen that the power factor is $\mathrm{R} / \mathrm{Z}$. For a purely resistive $\mathrm{AC}$ circuit, $\mathrm{R}=\mathrm{Z}$ and the power factor $=1$.

- Impedance

While Ohm's Law applies directly to resistors in DC or in AC circuits, the form of the current-voltage relationship in AC circuits in general is modified to the form: Impedance $\mathrm{Z}=\frac{V}{I}$ as per $\mathrm{V}=\mathrm{IR}$ for a pure resistor where $\mathrm{Z}=\mathrm{R}$ preserving the forms of the $\mathrm{DC}$ ohm's law.

\section{- Inverter Calculations}

The power consumption of each unit should be written on the side or back of the unit or will be stated somewhere in the specification sheet in the instruction manual. If not, we can use the equation below to work it out. P = V I Power (watts) = Voltage (V) x Current drawn in Amps (I) For example, for Tube light and for ceiling fan we take $40 \mathrm{wats} / \mathrm{hr}$ and $60 \mathrm{watts} / \mathrm{hr}$ Combo amps together use $40+60=100$ watts. Also we might want to take into consideration other losses that are not so obvious such as converting ac power back into dc for our equipment, ambient temperature, and general losses due to mechanics, age and wear and tear of all the gear involved. I reckon an extra $25 \%$ is a large enough excess. That would give us... $0.25 \times 100=25+100=125$ So we would need a continuous supply of 125 watts/hr. Bearing in mind an inverter will have an average efficiency rating of between 85 and $95 \%$, we can take the value of $90 \%$ and say the 125 watts we need to get out of the inverter on the other side will only be $90 \%$ of the power we need to put in to achieve that. So we have to multiply our $90 \%$ figure by some factor to work out the $100 \%$ figure we originally fed into the inverter to attain our $90 \%$ out. $90 \%$ x $1.1=99 \%$. If we multiply 125 watts by a factor of 1.1 we get $125 \times 1.1=137.5 \mathrm{w}$. This means in theory, if we input around 137.5 watts in one end, we'll get 125 out the other.

\section{Load estimation}

DC loads are usually 12 volts or a multiple of $12 \mathrm{~V}$. Generally, the efficiency and power handling capability are better for units operating at higher DC voltage. However, the advantages of the higher operating voltage is the lower current required to produce the same power. High current means large wire size, expensive and hard to get fuses, switches and connectors. Considering these factors, the operating voltage of the system is selected to be $12 \mathrm{~V}$ DC.

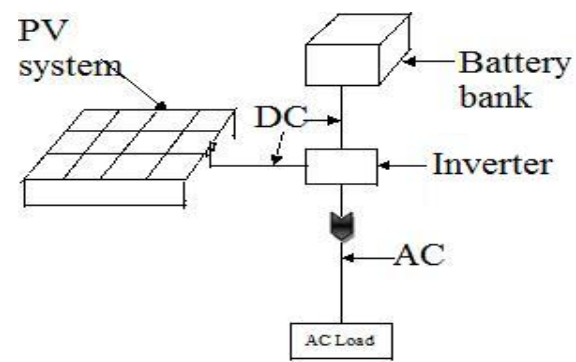

Fig.2. Schematic of a typical hybrid PV\& battery power system.

The energy demand (Ed) for residential load is given in watt-hour per day by $E_{d}(\mathrm{Wh})=\in_{i=1}^{n} N_{\mathrm{i}} I_{\mathrm{i}} V_{\mathrm{i}} H_{\mathrm{i}} \ldots \ldots \ldots \ldots . .(1)$ where, $N \mathrm{i}$ is the number of $i^{t h}$ residential load; $I \mathrm{i}, V \mathrm{i}$ are the current and 
voltage respectively drawn by the ith loads; $H \mathrm{i}$ is the daily duty cycle of the $i^{\text {th }}$ load (hrs/day). The load demand in Ampere-hour is given by

$E_{d(A h)}=\frac{E_{d(w h)}}{\eta_{p c e} V_{n s v}}=\frac{\epsilon_{i=1}^{n} N_{i} V_{i} H_{i}}{\eta_{p c e} V_{n s v}}$

Where, $\eta_{p c e}=$ power conversion efficiency; $V_{n s v}=$ nominal system voltage.

The peak current drawn by the total AC load is

$I_{p}=\frac{\in_{i=1}^{n} I_{i} V_{i}}{V_{n s v}}$

Corrected Ampere-hour load is given by

$E_{c(A h)}=\frac{E_{d(A h)}}{\eta_{w} \eta_{b}}$.

Where, $\eta_{w}$ is the wire efficiency and $\eta_{b}$ is the battery efficiency.

Table.1. Load estimation for AC appliances

\begin{tabular}{|c|c|c|c|c|}
\hline $\begin{array}{c}\text { Load } \\
\text { description }\end{array}$ & Quantity & $\begin{array}{l}\text { Load } \\
\text { Current } \\
\text { (A) }\end{array}$ & $\begin{array}{l}\text { Load } \\
\text { Voltage } \\
\text { (V) }\end{array}$ & $\begin{array}{c}\text { AC } \\
\text { load } \\
\text { Power } \\
\text { (W) }\end{array}$ \\
\hline $\begin{array}{l}\text { Fluorescent } \\
\text { lamp (AC) }\end{array}$ & 1 & 0.182 & 220 & 40 \\
\hline Ceiling fan & 1 & 0.272 & 220 & 60 \\
\hline $\begin{array}{c}\text { Load } \\
\text { description }\end{array}$ & $\begin{array}{l}\text { Daily } \\
\text { Duty } \\
\text { Cycle } \\
\text { hrs/day }\end{array}$ & $\begin{array}{c}\text { Power } \\
\text { Conversion } \\
\text { efficiency }\end{array}$ & $\begin{array}{l}\text { Nominal } \\
\text { System } \\
\text { Voltage } \\
\text { (V) }\end{array}$ & $\begin{array}{c}\text { Amp } \\
\text { Hour } \\
\text { Load } \\
(\mathrm{Ah} / \mathrm{da} \\
\mathrm{y})\end{array}$ \\
\hline $\begin{array}{l}\text { Fluorescent } \\
\text { lamp (AC) }\end{array}$ & 12 & 0.80 & 12 & 49.99 \\
\hline Ceiling fan & 12 & 0.80 & 12 & 74.99 \\
\hline Total AC loa & wer100W & \multicolumn{3}{|c|}{ Total Amp-Hour Load 124.98} \\
\hline
\end{tabular}

Total AC load power $=100 \mathrm{~W}$.

Total Amp-Hour Load = 119.98 (Ah/day).

Peak-current drawn $=8.33$ Amp.

Corrected Amp Hour Load = 124.98 (Ah/day).

IV. Cost Calculation

Table.2. Description about Component

\begin{tabular}{lllll}
\hline Component & Capacity & $\begin{array}{l}\text { Life } \\
\text { in } \\
\text { yr }\end{array}$ & $\begin{array}{l}\text { Price in } \\
\text { INR }\end{array}$ & Brand \\
& & & & \\
\hline Solar PV & $120 \mathrm{watt}$ & 20 & 12,000 & $\begin{array}{l}\text { Poly } \\
\text { Crystalline }\end{array}$ \\
Battery & $130 \mathrm{amp}$ & 3 & 13,000 & Exide \\
Inverter & $128 \mathrm{VA}$ & 15 & 5500 & Sukam \\
Cable & - & - & 3000 & R.R \\
Structure & - & - & 3000 & - \\
Installation Cost & & & 3000 & \\
\multicolumn{2}{c}{ Total Cost $=39,500$} & & &
\end{tabular}

\section{Conclusion}

The theoretical calculations used in this design are found to be in agreement with the practical performance of the system. It is observed that the PV array can supply power to operate the AC appliances for twelve hours per day. Power supply with this system is completely eco friendly and most effective in month of February to June. This type of system is also economical for large scale power production like in $\mathrm{kw}$ or gw. It is found that tilt angle at $\varnothing-15^{\circ}$ is better for the months April-September (i.e. for summer period) and $\varnothing+15^{\circ}$ for the months October-March (winter period).

\section{References}

[1]. Duffie ZA, Beckman WA. Solar engineering of thermal processes. New York: John Wiley and Sons, 1990.

[2]. Boer KW et al. Materials for solar photovoltaic energy conversion, Annual Review of Material Science, M6, 303.

[3]. Groumpos PP et al. An optimal sizing method for stand-alone photovoltaic power systems. Solar Energy 1987;38(5):341-51.

[4]. Stand Alone Photovoltaic Power systems. A Hand Book of Recommended Design Practics. Sandia National Laboratories, USA, 1991. 
[5]. Hussain M, Huda, Ainul, Optimization of the tilt angle for inclined collectors at Dhaka In: Proc. World Renewable Energy Congress, 1996.

[6]. Hussain M, et al. A study of solar radiation in Dhaka. In: Proceedings of the National Solar EnergyConvention, India, pp. 103-5, 1995. 